\title{
Long-term sea-level projections with two versions of a global climate model of intermediate complexity and the corresponding changes in the Earth's gravity field
}

\author{
O. Makarynskyy ${ }^{*}$, M. Kuhn, W. E. Featherstone \\ Western Australian Centre for Geodesy, Curtin University of Technology, GPO Box U1987, \\ Perth, WA 6845, Australia
}

\begin{abstract}
Approximate estimations of future climate change can be produced by implementing numerical global climate models. In this study, versions 2.6 and 2.7 of the University of Victoria Earth System Climate Model (ESCM) were employed. Compared to other climatic projections, the novelty of this study consists in a significant extension of the projection period to the time-scale of 4200 years, and in comparisons of the results obtained with two sequential versions 2.6 and 2.7 of ESCM. Version 2.6 of ESCM couples the atmospheric, oceanic and ice processes. Version 2.7 of ESCM accounts for solar and ice-sheet forcing, as well as coupling land-vegetation-atmosphere-ocean carbon, and allows inclusion of ocean biology and dynamic vegetation modules. Our comparison exhibits essential quantitative and, moreover, qualitative differences in the parameters under consideration, which are surface air temperature, sea-ice and snow volumes, and surface pressure in a column of water averaged globally. The observed differences are attributed to the biological blocks added to ESCM version 2.7, changed numerics and explicit ice-sheet forcing. Fur thermore, the non-steric sealevel change has been used to model corresponding gravity field changes (here in terms of

* Correspond ing author: Tel: +61 89266 7398; Fax: +61 89266 2703;

E-mail: O.Makarynskyy@curtin.edu.au
\end{abstract}


geoid height) by evaluating Newton's volume integral and study the differences between the two software versions under consideration. In line with the model results, the estimated geoid height changes also exhibit a significant difference between the experiments' outcomes.

Keywords: Climate; Modelling; Snow and Ice melt; Sea level change; Gravity field change

\section{Introduction}

For the last few decades, global environmental change has attracted particular attention, not only to the scientific community (e.g. Braganza et al., 2003; Manabe and Stouffer, 1979), but also to the general public (e.g. Kolbert, 2005). Special focus is given to a change in global sea-level as an indicator of environmental change. This is due to the possible socioeconomic impact of any long-term change, such as inundation of coastal cities. Furthermore, a longterm sea-level rise will have a great impact on population and infrastructure of low-lying nearshore areas (e.g. Intergovernmental Panel on Climate Change, 2001).

Even though the numerical weather/climate predictions is an arguable subject in itself (e.g. Lorenz, 1967) and the present-day estimates of individual components such as thermal expansion (eustatic), fresh-water influx due to melting of snow and land ice, as well as terrestrial water storage influencing the global sea-level, are highly uncertain (e.g., Cazenave and Nerem, 2005), scientists from different branches of geoscience are now embarking on future sea-level predictions (e.g. Rignot et al., 2003; Sun and Hansen, 2003).

Predictions of atmosphere and/or ocean parameters with high spatial and temporal resolution can be obtained from three-dimensional numerical global climate models. Such models are comprehensive in the sense that they are able to give a detailed description of, for 
instance, individual weather systems in the atmosphere and/or regional currents in the ocean. These models account for these physical processes by adopting deterministic expressions and parameterisations available at the time of release.

Nevertheless, even the most modern computational facilities do not provide sufficient power to run either multiple and/or long time-scale (e.g., hundred to thousand years) experiments using these comprehensive global climate models because they are very demanding on computational time and recourses. Meanwhile, in long-term climate projections, only general trends of the main processes are of interest, so high temporal resolution and detailed descriptions are probably excessive.

Therefore, most of the studies that tackle long-term sea-level variations on time-scales from hundreds to thousands of years employ two other types of models, namely conceptual global climate models and climate models of intermediate complexity. Inductive (or tutorial) models of the first type are very simplistic, frequently one- or two-dimensional, and only consider the main processes taking place in the system Earth (e.g. Paillard, 1998).

Models of the second type (e.g. Claussen et al., 2001) embed the best features from both comprehensive and conceptual climate models using some acceptable simplifications for some processes of lesser importance, in parallel with more detailed deterministic description of other processes, which may be of greater importance to a particular scholar or project team. Thanks to their relative simplicity, these models allow for long-term (e.g. tens of thousands of years) and/or an essential number of sensitivity experiments (e.g. Church et al., 2001). To emphasize the fact that the outcomes of such long-term predictions cannot yet be validated, they are usually called projections.

In this study, the University of Victoria Earth System Climate Model (ESCM; Weaver et al., 2001) was employed. This model is of the above second type, numerically representing the primary thermodynamic and hydrological components of the Earth's climate system in a 
spherical grid. The surface balances and feedbacks of heat, freshwater and momentum of impulse are described using a diffusive energy-moisture balance atmospheric module. General ocean circulation is simulated using primitive equations of motion. The thermodynamics and elastic-viscous plastic dynamics of sea-ice are represented by modules with different levels of complexity involving some parameterizations and the momentum balance equations.

The ESCM model was selected because all the model modules are available to download from a public domain website (http://wikyonos.seos.uvic.ca/model/), and the model developers claim that it is able to represent present-day climate reasonably well (Weaver et al., 2001) when validating model results versus actual measurements. This was also demonstrated in that the model provides a reliable basis for estimation of global thermohaline circulation (e.g. Weaver et al., 1999), the past climates (e.g. Weaver et al., 1998 and 2003; Cottet-Puinel et al., 2004), as well as - most importantly for this study - long-term (up to year 2500 A.D.) future climate projections (e.g. Weaver et al., 2001).

In the present study, results obtained from two subsequent versions (2.6 and 2.7) of the ESCM are compared in order to clarify how the recent upgrade affects projections of longterm sea-level change and corresponding changes in the Earth's gravity field (notably the geoid). This study focuses solely on the changes of sea-level and gravity field; thus a more comprehensive description and analysis of other global climate changes lie beyond the scope of this paper. Both ECSM model versions have been applied to a greenhouse-warming scenario using a $2 \%$ annual increase of the initial concentration (365 ppm in year 2000) of carbon dioxide $\left(\mathrm{CO}_{2}\right)$. Therefore, the difference in results can be solely attributed to the changes introduced in the 2.7 version of ESCM. 


\section{Computational recourses and software employed}

ESCM can be run (and was tested here) on different platforms operating under, e.g., AIX, DARWIN, IRIX, Linux, and some others. In this study, a PC with Pentium IV $2.80 \mathrm{GHz}$ processor and $1.00 \mathrm{~GB}$ of RAM ran under Mandrake Linux v.8.2 was used. The Mandrake (later on Mandriva, http://www.mandriva.com/) Linux operating system is an open source [free] software. To compile the ECSM model, another freely downloadable software, the Intel Fortran Compiler for Linux (http://www.intel.com/cd/software/products/asmona/eng/compilers/flin/219857.htm), was installed and implemented.

A 100-year projection period had been taking a little more than one day of clock time, while the real-time computations had taken about two months in total. To avoid data loss related to occasional power outages in Western Australia, the model was executed using the command allowing for running it in consecutive steps saving 10-year averaged results over 200-year model periods. Under these conditions, each NetCDF archive with 200-year 2D and 3D computational outcomes has a size of about $100 \mathrm{MB}$.

During a model run, the results can easily be visualised using the freely available NetCDF (Network Common Data Form, http://www.unidata.ucar.edu/software/netcdf/) interface as the data are saved in NetCDF archives. The interface and associated library were developed by the Unidata Program at the University Corporation for Atmospheric Research as a machineindependent format for representing scientific data. To numerically analyse and plot the results of the model runs, the MatLab computing environment with a suitable NetCDF Toolbox was used, which is also available from the public domain (http://www.unidata.ucar.edu/software/netcdf/software.html\#MATLAB). 


\section{Description of the ESCM versions 2.6 and 2.7 and parameters used}

Version 2.6 of the ESCM was made available for public use in January 2003 (http://wikyonos.seos.uvic.ca/mode1/2.6.html). This version numerically represents the primary thermodynamic and hydrological components of the Earth's climate system by coupling the atmosphere-ocean-ice processes. The surface balances and feedbacks of heat, freshwater and momentum of motion are described in the atmospheric module based on Fanning and Weaver's (1996) diffusive energy-moisture balance. General ocean circulation is modelled by the Modular Ocean Model (MOM 2; Pacanowski, 1996) using primitive equations of motion. Parameterizations and the momentum-balance equations are used to describe the thermodynamics and elastic-viscous plastic dynamics of sea-ice (e.g., Semtner, 1976; Bitz et al., 2001; Holland et al., 2001). Land ice sheets were not included in this version of the ECSM model.

In July 2004, a new version of the ECSM model appeared (http://wikyonos.seos.uvic.ca/climate-lab/model.html). This version 2.7 includes new modules of ocean biology and dynamic vegetation (Cox, 2001; Cox et al., 2001), coupled carbon coming from land-vegetation-atmosphere-ocean, and accounts for solar and ice-sheet forcing. Some numerics of the model were also changed (Michael Eby, 2006, pers. comm.). The Greenland and Antarctic ice sheets remain constant under the used scenario because the landice dynamics are not considered, as the land-ice module is not yet publicly available.

In this study, the total period over which the computations were performed was 4200 model years. First, both versions of the model were run from "cold start" in year 0 until year 2000 under default model options with present-day (2005) radiative forcing in a spherical grid with latitudinal resolution of $3.6^{\circ}$ and longitudinal resolution of $1.8^{\circ}$ (i.e., 100 by 100 nodes). Confirming Weaver et al. (2001), the results of such a preliminary run are in good agreement 
with the present-day climate and provide stable (zero or near-zero yearly averaged drifts of the parameters under consideration) initial conditions for further climate experiments.

After that, starting from year 2000, the two versions of the ESCM models were forced with a linear $2 \%$ per year $\left(7.3 \mathrm{ppm}_{\text {year }}{ }^{-1}\right) \mathrm{CO}_{2}$ increase rate and were run for 2200 years more (Fig. 1). This period was selected because, under this scenario, version 2.6 shows similar results to the ones demonstrated by Makarynskyy et al. (2005), i.e., respective complete and more than half melt of the initial sea-ice and snow volumes averaged globally.

We are aware that the selected climatic scenario leads to $\mathrm{CO}_{2}$ concentrations that are higher than 15000 ppm by the end of the computations. Meanwhile, even in the case the known reserves of fossil fuel ( $\sim 5000 \mathrm{Gt})$ were burnt and kept in the atmosphere, the concentration would be around $12000 \mathrm{ppm}$. Therefore, such a scenario is rather unrealistic reflecting some artificially induced climate change produced by some arbitrarily specified thermal forcing. Nevertheless, the use of the specified $\mathrm{CO}_{2}$ increase rate over the indicated 2000-year period allowed shortening the total time needed to accomplish computational experiments and to estimate changes in the Earth's gravity field induced by sea ice and snow melting.

\subsection{Oceanic parameters}

The remaining sea-ice and snow volumes are of special importance here because they determine sea-level changes due to the sea-water volume/mass increase. The other important model variables are surface air temperature (SAT; measured/modelled at $\sim 1.5 \mathrm{~m}$ above the underlying surface) and surface pressure $\left(P_{s}\right)$ in a column of water. The latter is regarded as the implicit ocean-free surface in terms of pressure under the rigid lid approximation used in 
MOM2 (Pacanowski, 1996). Such an approximation excludes the high-frequency external gravity waves from consideration and thus speeds up the computations.

An estimate of sea-level height change $\Delta H_{m}$ (between two time instants) due to any oceanwater mass change (non-steric sea-level change) can be easily derived from the surface water pressure change $\Delta P_{s}$ as

$$
\Delta H_{m}(\Omega)=\frac{\Delta P_{s}(\Omega)}{\rho_{s}(\Omega) g(\Omega)}
$$

where $\rho_{s}$ is the surface water layer density, and $g$ is the gravitational acceleration computed as a function of latitude (e.g., Moritz, 1980). Here $\Omega=(\lambda, \theta)$ denotes the coordinate pair of spherical longitude $\lambda$ and co-latitude (polar distance) $\theta$.

To evaluate global steric sea-level change $\Delta H_{s t}$ in each computational grid node between years 2000 and 4200, the following expression was used:

$$
\Delta H_{s t}(\Omega)=C \cdot \Delta T \cdot D
$$

where $C$ is the coefficient of water thermal expansion (e.g. Knauss, 1979; McDougall, 1987):

$$
C=-\frac{1}{\rho} \cdot \frac{\partial \rho}{\partial T}
$$

where $T$ is the mean water layer temperature, and $\Delta T$ is the temperature change between years 2000 and $4200 ; \rho$ is the mean water-layer density calculated as a function of the water temperature, salinity and pressure at a certain depth; and $D$ is the water layer thickness. There are 19 water layers from $0 \mathrm{~m}$ to $5396 \mathrm{~m}$ considered in the ESCM runs.

Finally, the total sea-level change is given by the sum of the sea-level changes caused by the ocean-water mass change (cf. Eq. 1) and the steric sea-level change (cf. Eq. 2), i.e.,

$$
\Delta H(\Omega)=\Delta H_{m}(\Omega)+\Delta H_{s t}(\Omega)
$$

The non-steric sea-level change $\Delta H_{m}$ has been taken here as a measure to indicate water-mass changes throughout the global ocean. 


\subsection{Geodetic parameters}

The water-mass changes can be converted into changes of the Earth's gravity field (here in terms of geoid height) either in the space domain by numerical integration or in the frequency domain by expressing Newton's integral as a spherical harmonic expansion by evaluating Newton's volume integral (e.g., Kuhn and Featherstone, 2003; Kuhn and Seitz, 2005).

Following the latter approach, the gravitational potential $V(\Omega, r)$ at location $(\Omega, r)$, where $r$ stands for the radial distance measured from the geocentre to $(\Omega, r)$, located on or above the mean reference sphere with radius $R$ is expressed by

$$
V(\Omega, r)=\sum_{n=0}^{N_{\max }}\left(\frac{R}{r}\right)^{n+1} \sum_{m=-n}^{n} \bar{V}_{n m} \bar{Y}_{n m}(\Omega)
$$

with the fully normalised spherical harmonic coefficients $\bar{V}_{n m}$ and the surface spherical harmonics (e.g., Hobson, 1955)

$$
\bar{Y}_{n m}(\Omega)=\left\{\begin{array}{cc}
\bar{P}_{n m}(\cos \theta) \cos m \lambda & m \geq 0 \\
\bar{P}_{n|m|}(\cos \theta) \sin |m| \lambda & m<0
\end{array}\right.
$$

In Eq. (6), $\bar{P}_{n m}(\cos \theta)$ denotes the associated Legendre functions of the first kind for degree $n$ and order $m$ (e.g., Heiskanen and Moritz, 1967).

The fully normalized spherical harmonic coefficients are given by an infinite sum of spherical harmonic coefficients $\bar{\kappa}_{p, n m}$ representing surface density functions (e.g., Ramillen, 2002; Kuhn and Featherstone, 2003)

$$
\bar{V}_{n m}=\frac{4 \pi G R}{2 n+1} \cdot \sum_{p=1}^{\infty} \frac{\Gamma(n+3)}{p ! \Gamma(n+4-p)} \bar{\kappa}_{p, n m}
$$

assuming that the surface mass layer is referred to the reference sphere $(r=R)$. In Eq. (7), $p$ is the order of approximation, and $\Gamma(\bullet)$ denotes the gamma function and the fully normalized spherical harmonic coefficients $\bar{\kappa}_{p, n m}$ of the surface density functions are given by 


$$
\kappa_{p}(\Omega)=\rho(\Omega) \frac{\Delta H_{m}(\Omega)^{p}}{R_{L}^{p-1}}, \quad p \in N^{+}
$$

Here, the surface density function is expressed by the ocean water-mass changes described by the non-steric sea-level change $\Delta H_{m}$ (cf. Eq. 1) and the density of ocean water $\rho(\Omega)$ (here a constant mass-density of $1027 \mathrm{~kg} \mathrm{~m}^{-3}$ has been applied).

Using the change in gravitational potential (cf. Eq. 5) the change in geoid height is given by Bruns's formula (e.g. Rummel and van Gelderen, 1995, 1999)

$$
N(\Omega)=\frac{V(\Omega)}{\gamma}=\sum_{n=0}^{N_{m a x}} \sum_{m=-n}^{n} \bar{N}_{n m} \bar{Y}_{n m}(\Omega)
$$

where $V(\Omega, r)$ is evaluated on the reference sphere $(r=R), \gamma$ is normal gravity on the reference ellipsoid, and the spherical harmonic coefficients for the geoid height are given by (cf. Eq. (7) divided by $\gamma$ )

$$
\bar{N}_{n m}=\frac{\bar{V}_{n m}}{\gamma}
$$

It should be mentioned that the latter approach assumes the Earth to be a rigid body, thus neglecting any visco-elastic response to the ocean water mass changes.

\section{Comparisons of results from the ESCM versions 2.6 and 2.7}

The top panel of Fig. 1 gives a graphical representation of the $\mathrm{CO}_{2}$ scenario used in our model experiments from year 0 to 4200 , as well as a time-series of the estimated SAT averaged globally and at 10-year time intervals. A comparison of the SAT graphs (Fig. 1) demonstrates that in the preliminary model runs up to present-day conditions (year 2000) the models produce a similar SAT, although version 2.7 gives slightly higher values (by about $0.5^{\circ} \mathrm{C}$ ). Furthermore, the seasonal variations (bottom panel of Fig. 1) of the SAT is similar for 
both versions with version 2.7 having higher minimum values (about $1^{\circ} \mathrm{C}$ ). The picture changes drastically when the $\mathrm{CO}_{2}$ concentration starts to increase: the SAT in version 2.6 grows quickly, quasi-logarithmically, from about $14^{\circ} \mathrm{C}$ to $30^{\circ} \mathrm{C}$ while version 2.7 demonstrates much slower SAT increase from about $14.5^{\circ} \mathrm{C}$ to $17^{\circ} \mathrm{C}$.

Such differences in the SAT significantly influence the rate at which snow and sea-ice melt. This is demonstrated in the top panels of Figs. 2 and 3, which show the temporal evolution of global averages of the snow and sea-ice volume, respectively. Notably, the volumes of snow and sea-ice accumulated by the ECSM models in the preliminary experiments, as well as their seasonal variations (see the bottom panels of Figs. 2 and 3), are essentially larger from version 2.6 producing about $6 \times 10^{13} \mathrm{~m}^{3}$ of snow and about $8 \times 10^{12} \mathrm{~m}^{3}$ of sea-ice more than version 2.7 for the same 2000-year time period. The ECSM model developers found the agreement between version-2.6-simulated and observed present-day ice satisfying, acknowled ging that the ESCM overestimates the ice thickness (Weaver et al., 2001).

In the version 2.6 ESCM experiment, the process of melting occurs in complete correspondence with the SAT increase: almost linearly for snow decreasing its volume more than twice from $16 \times 10^{13} \mathrm{~m}^{3}$ to $7 \times 10^{13} \mathrm{~m}^{3}$, and in a very steep, "collapsing" fashion for the sea-ice volume that decreases from $18 \times 10^{12} \mathrm{~m}^{3}$ to almost zero in 2200 years' time. The same consideration applies to version 2.7 ECSM model run, in which a slower SAT increase produces a slower melting of both snow and sea-ice. Therefore, by the end of the experiment, there are still about $10.5 \times 10^{13} \mathrm{~m}^{3}$ of snow and $5 \times 10^{12} \mathrm{~m}^{3}$ of sea ice, which are about $87.5 \%$ and $62.5 \%$ of the initial volumes, respectively.

Seemingly, the inclusion of the Greenland and the Antarctic ice sheets in version 2.7 of ESCM has resulted in almost no seasonal variations in snow volume (bottom panel of Fig. 2) because the ice sheets provide some room for snow accumulation missing in the previous version 2.6 of ESCM. 
The latitudinally averaged SAT and surface lid pressure $P_{s}$ for year 4200 are presented in Fig. 4. The plots of SAT from both these models show very similar curves, though with overall lower temperatures of about $10^{\circ} \mathrm{C}$ to $15^{\circ} \mathrm{C}$ for version 2.7. Results for the $P_{s}$ latitudinal variations differ significantly in the polar regions where version 2.6 produces much lower values by around $10,000 \mathrm{~kg} \mathrm{~m}^{-1} \mathrm{~s}^{-2}$ in the Arctic and $25,000 \mathrm{~kg} \mathrm{~m}^{-1} \mathrm{~s}^{-2}$ in Antarctica. In the mid-latitude and equatorial regions, instead, version 2.6 produces slightly higher values than version 2.7. Therefore, in version 2.6 , more water is moved from the polar regions into midlatitude and equatorial regions by oceanic currents and due to lesser gravitational attraction.

The averaged differences in sea-surface temperature (SST) from both these model versions (Fig. 5) generally show similar tendencies, although with values smaller by one order of magnitude from version 2.7. Such differences between versions 2.6 and 2.7 are related to a significantly lower SAT in the latest version experiment. A prominent feature present in these both latitudinal distributions is that between $30^{\circ} \mathrm{S}$ and $70^{\circ} \mathrm{S}$, the SST is higher by about $4^{\circ} \mathrm{C}$ comparatively to the Equatorial water, which would be expected to be the warmest. This feature is attributed to the heating of the continuous water "belt" in the Southern Hemisphere under our employed $\mathrm{CO}_{2}$ scenario.

As a consequence of the differences in air temperature, water temperature and surface pressure (or water mass) distributions, the total sea level change between the years 2000-4200 obtained from the two model versions are different (Fig. 6). To a great extent, these total changes result from steric sea-level changes. In general, the sea-level changes obtained from version 2.6 are one order of magnitude larger than those obtained from version 2.7. Furthermore, significant differences can be seen in the Antarctic region, as well as in midlatitude and equatorial regions (Fig. 6).

Firstly from Fig. 6, there is a sharp "spike" next to the North Pole points, followed by a decrease in the total sea-level change. Secondly, the absolute minimum present at about $80^{\circ} \mathrm{S}$ 
in the version 2.6 experiment (Fig. 6, top panels) is also reproduced by version 2.7 though moved slightly northwards. Therefore, independently of overall significant discrepancies in the obtained outcomes, the sea-level changes in the Arctic and Antarctic are driven by similar processes in both these models.

The spatial distribution of the non-steric and steric sea-level change, as well as the total sealevel change, from the model versions 2.6 and 2.7 are illustrated in Figs. 7-9. As mentioned above, most of the total sea-level change is due to the steric effect (i.e., mostly thermal expansion). The results shown in Fig. 7 show a similar structure with overall negative values in the polar region and positive values in mid-latitude regions. The parameters under consideration from the version 2.7 , however, demonstrate values smaller by one order of magnitude.

\section{Discussion}

This study has compared some model results obtained from the ESCM versions 2.6 and 2.7. It was shown that both versions produce essentially different outcomes under the same atmospheric $\mathrm{CO}_{2}$ increase scenario. Therefore, the significantly different results can be attributed to the different forcing functions used by the two models, particularly the absence and the presence of the ice-sheet forcing in version 2.6 and 2.7, respectively. Clearly, introduction of the Greenland and Antarctic ice sheets in version 2.7, which worked as large scale "coolers", contributed to a much slower rate of SAT increase. On the other hand, the inclusion of the dynamic vegetation and ocean biology modules in version 2.7 probably resulted in further consumption of atmospheric $\mathrm{CO}_{2}$ and thus acted also towards a slowing 
down of the rate of global warming. However, further studies are necessary, which lie beyond the scope of the present study.

The changes in the model numerics and climatic forcing resulted in very different volumes of snow and sea-ice accumulated by the models during our preliminary 2000-year runs (Figs. 2 and 3). Therefore, we expected that the smaller snow and sea-ice volumes from version 2.7 would melt much faster than significantly larger ones from version 2.6, but this was not the case due to a much slower atmosphere/ocean water temperature increase. Under the influence of much slower warming in the version 2.7 experiment, these parameters were not changed to a significant extent and, therefore, contributed very little to the non-steric sea-level change from year 2000 to 4200 (Fig. 6), which was proportional to the total mass change for this period. Meanwhile, the steric sea-level changes, which virtually determined the total sea-level changes in both models, followed the general trend in the air and water temperature, which was much weaker in version 2.7 .

The non-steric sea-level change was taken to derive the effect on the gravity field. Here, the geoid height changes given by Eqs. (9-10) were calculated. The geoid height changes represent the vertical change of the particular equipotential surface best coinciding with the initial sea-level. In order to derive the necessary spherical harmonic coefficients of the equipotential change, only the linear term of Eq. (7) was evaluated. This term accounts for about $95 \%$ of the total signal (e.g. Rummel et al. 1988, Kuhn and Featherstone 2003). The geoid height change obtained from ECSM models 2.6 and 2.7 are illustrated in Fig. 10, also exhibiting a difference of one order of magnitude. The gravity fields' structure is similar to, but much smoother than, that of the total sea-level change because gravity potential is a smoother function.

The similar structure of the non-steric sea-level changes (cf. Fig. 7) and the corresponding geoid changes (Fig. 10) show that our ECSM-obtained sea-level changes are realistic in the 
sense that the new sea-level represents in general an equipotential surface. This means that the gravitational attraction effect has been included in its determination (e.g., Farrell and Clark, 1976).

\section{Endnote}

It must be noted that the later upgrade (version 2.7) of ESCM is considered to be more realistic because it explicitly includes the polar and Greenland ice sheets, thus providing closer to the present-day climate initial conditions than version 2.6. Therefore, the future research in this direction will be focussed on the complete melting of the accumulated by year 2000 snow and sea-ice in order to estimate a realistic time span during which this can happen. Additional sensitivity experiments will be performed with recent upgrades of the ESCM to clarify the role of different model components of the system Earth.

Acknowledgments. This study was funded by Australian Research Council (ARC) Discovery Project grant DP0345583 and a 2006 Curtin University Strategic Research Grant. We are grateful to Michael Eby for technical assistance with the ESCM installation and some useful discussions of the results obtained. The anonymous reviewers and editor are acknowledged for their constructive remarks. 


\section{References}

Bitz, C.M., Holland, M.M., Weaver, A.J., Eby, M., 2001. Simulating the ice-thickness distribution in a coupled climate model. Journal of Geophysical Research 106, 2441-2464.

Braganza, K., Karoly, D.J., Hirst, A.C., Mann, M.E., Stott, P., Stouffer, R.J., Tett, S.F.B., 2003. Simple indices of global climate variability and change: Part I - variability and correlation structure. Climate Dynamics 20, 491-502.

Cazenave, A., Nerem, R.S., 2005. Present-day sea level change: observations and causes. Review of Geophysics 42, RG3001.

Church, J.A., Gregory, J.M., Huybrechts, P., Kuhn, M., Lambeck, K., Nhuan, M.T., Qin, D., Woodworth, P.L., 2001. Changes in Sea level. In: Houghton, J. T., Ding, Y., Griggs, D.J., Noguer, M., van der Linden, P. J., Xiaosu, D. (Eds.), Climate Change 2001: The Scientific Basis. Cambridge University Press, UK, pp. 639-693.

Claussen, M., Mysak, L.A., Weaver, A.J., Crucifix, M., Fichefet, T., Loutre, M.-F., Weber, S.L., Alcamo, J., Alexeev, V.A., Berger, A., Calov, R., Ganopolski, A., Goosse, H., Lohman, G., Lunkeit, F., Mokhov, I.I., Petoukhov, V., Stone, P., Wang, Zh., 2001. Earth system models of intermediate complexity: closing the gap in the spectrum of climate system models. Climate Dynamics 18, 579-586.

Cottet-Puinel, M., Andrew J. Weaver, A.J., Hillaire-Marcel, C., de Vernal, A., Clark, P.U., Eby, M., 2004. Variation of Labrador Sea Water formation over the Last Glacial cycle in a climate model of intermediate complexity. Quaternary Science Reviews 23, 449-465.

Cox, P.M., 2001. Description of the "TRIFFID" Dynamic Global Vegetation Model. Hadley Centre technical note 24, Met Office, Bracknell, UK. (http://climate.uvic.ca/common/HCTN_24.pdf) 
Cox, P.M., Betts, R.A., Jones, C.D., Spall, S.A., Totterdell, I.J., 2001. Modelling Vegetation and the Carbon Cycle as Interactive Elements of the Climate System. Hadley Centre technical note 23, Met Office, Bracknell, UK. (http://climate.uvic.ca/common/HCTN_23.pdf)

Fanning, A.G., Weaver, A.J., 1996. An atmospheric energy-moisture model: Climatology, interpentadal climate change and coupling to an ocean general circulation model. Journal of Geophysical Research 101, 15111-15128.

Farrell, W.E., Clark, J.A., 1976. On postglacial sea level. Geophysical Journal of the Royal Astronomic Society 46, 647-667.

Heiskanen, W.A., Moritz, H., 1967. Physical Geodesy. W.H. Freeman, San Francisco. 364 pp.

Hobson, E.W., 1955. The Theory of Spherical and Ellipsoidal Harmonics. Chelsea Publishing Company, New York. 500 pp.

Holland, M.M., Bitz, C.M., Eby, M., Weaver, A.J., 2001. The role of ice ocean interactions in the variability of the North Atlantic thermo-haline circulation. Journal of Climate 14, 656675.

Intergovernmental Panel on Climate Change, 2001. IPCC Third Assessment Report-Climate Change 2001: Impacts, Adaptation and Vulnerability. Cambridge University Press, UK. $1032 \mathrm{pp}$.

Knauss, J.A., 1997. Introduction to Physical Oceanography. Prentice-Hall, Englewood Cliffs, New Jersey. 309 pp.

Kolbert, E., 2005. The Climate of Man - I. Disappearing islands, thawing permafrost, melting polar ice. How the earth is changing. The New Yorker April 25.

Kuhn, M., Featherstone, W.E., 2003. On the optimal spatial resolution of crustal mass distributions for forward gravity field modelling. In: Tziavos, I.N. (Ed.), Gravity and Geoid 
2002, Proceedings of the 3rd meeting of the International Gravity and Geoid Commission, Thessaloniki, Greece, pp. 195-200.

Kuhn, M., Seitz, K., 2005. Evaluation of Newton's integral in space and frequency domain. In: Sansò, F. (Ed.), A Window on the Future of Geodesy, IAG Symposia, Springer, Berlin, Heidelberg, New York, pp. 386-391.

Lorenz, E.N., 1967. The Nature and theory of the general circulation of the atmosphere. World Meteorologic Organization, Geneva. 161 pp.

Makarynskyy, O., Kuhn, M., Featherstone, W. E., 2005. Modelling future sea level change under greenhouse warming scenarios with an earth system model of intermediate complexity. In: Jekeli, C., Bastos, L., Fernandes J. (Eds.), Gravity, Geoid and Space Missions, Springer, Berlin, pp. 260-265.

Manabe, S., Stouffer, R.J., 1979. A CO2-climate sensitivity study with a mathematical model of the global climate. Nature 5738 (282), 491-493.

Moritz, H., 1980. Advanced Physical Geodesy. Wichmann, Abacus Press, Karlsruhe Germany. 500 pp.

McDougall, T.J., 1987. Neutral surfaces. Journal of Physical Oceanography 17, 1950-1964.

Pacanowski, R.C., 1996. MOM 2 Version 2 Documentation User's Guide and Reference Manual. GFDL Ocean Technical Report 3.2. Princeton, USA. (http://www.ocgy.ubc.ca/ yzq/books/MOM3/guide_parent.html)

Paillard, D., 1998. The timing of Pleistocene glaciations from a simple multiple-state climate model. Nature 191, 378-381.

Rignot, E., Rivera, A., Casassa, G., 2003. Contribution of the Patagonia icefields of South America to sea level rise. Science 297, 1502-1506.

Ramillen, G., 2002. Gravity/magnetic potential of uneven shell topography. Journal of Geodesy 76, 139-149. 
Rummel, R., Rapp, R.H., Sünkel, H., 1988. Comparisons of global topographic/iso static models to the Earth's observed gravity field. Report 388, Dept.of Geodetic Sciences and Surveying, Ohio State Univ, Columbus.

Rummel, R., van Gelderen, M., 1995. Meissl scheme - spectral characteristics of physical geodesy. Manuscripta Geodaetica 20, 379-385.

Rummel, R., van Gelderen, M., 1999. From the generalized Bruns transformation to variations of the solution of the geodetic boundary value problem. Technical Reports Department of Geodesy and Geoinformatics., Geodätisches Institut der Universität Stuttgart, Stuttgart, Germany. pp. 397-412.

Semtner, A.J., 1976. A model for the thermodynamic growth of sea ice in numerical investigations of climate. Journal of Physical Oceanography 6, 379-389.

Sun, S., Hansen, J.E., 2003. Climate simulations for 1951-2050 with a coupled atmosphereocean model. Journal of Climate 16, 2807-2826.

Weaver, A.J., Bitz, C.M., Fanning, A.F., Holland, M.M., 1999. Thermohaline circulation: high-latitude phenomena and the difference between the Pacific and Atlantic. Annual Reviews of Earth and Planetary Sciences 27, 231-285.

Weaver, A.J., Eby, M., Fanning, A.F., Wiebe, E.C., 1998. Simulated influence of carbon dioxide, orbital forcing and ice sheets on the climate of the Last Glacial Maximum. Nature 394 (6696), 847-853.

Weaver, A.J., Eby, M., Wiebe, E.C., Bitz, C.M., Duffy, P.B., Ewen, T.L., Fanning, A.F., Holland, M.M., MacFadyen, A., Damon Matthews, H., Me issner, K.J., Saenko, O., Schmittner, A., Wang, H., Yoshimori, M., 2001. The UVic Earth System Climate Model: model description, climatology, and applications to past, present and future climates. Atmosphere-Ocean 39(4), 361-428. 
Weaver, A.J., Saenko, O.A., Clark, P.U., Mitrovica, J.X., 2003. Meltwater pulse 1A from Antarctica as a trigger of the Bølling-Allerød warm in terval. Science 299, 1709-1713. 


\section{List of figures}

Figure 1. Globally and 10-yearly averaged surface air temperature and $\mathrm{CO}_{2}$ variations (top panel) as well as results for years 1998-1999 (bottom panel) obtained with versions 2.6 and

\section{7 of ESCM}

Figure 2. Globally and 10-yearly averaged snow volume variations (top panel) as well as results for years 1998-1999 (bottom panel) obtained with versions 2.6 and 2.7 of ESCM

Figure 3. Globally and 10-yearly averaged sea-ice volume variations (top panel) as well as results for years 1998-1999 (bottom panel) obtained with versions 2.6 and 2.7 of ESCM

Figure 4. Latitudinally averaged surface air temperature (SAT) and surface pressure in a column of water obtained with versions 2.6 and 2.7 of ESCM for year 4200

Figure 5. Latitudinally averaged sea-surface temperature (SST) changes between years 2000 and 4200 obtained with versions 2.6 and 2.7 of ESCM

Figure 6. Latitudinally averaged steric and total sea-level changes between years 2000 and 4200 obtained with versions 2.6 (top panels) and 2.7 (bottom panel) of ESCM

Figure 7. Non-steric sea level changes (in $\mathrm{mm}$ ) between years 2000 and 4200 obtained with versions 2.6 (top panel) and 2.7 (bottom panel) of ESCM

Figure 8. Steric sea-level changes (in $\mathrm{mm}$ ) between years 2000 and 4200 obtained with versions 2.6 (top panel) and 2.7 (bottom panel) of ESCM 
Figure 9. Total sea-level changes (in $\mathrm{mm}$ ) between years 2000 and 4200 obtained with versions 2.6 (top panel) and 2.7 (bottom panel) of ESCM

Figure 10. Geoid height changes (in m) between years 2000 and 4200 obtained with versions 2.6 (top panel) and 2.7 (bottom panel) of ESCM 


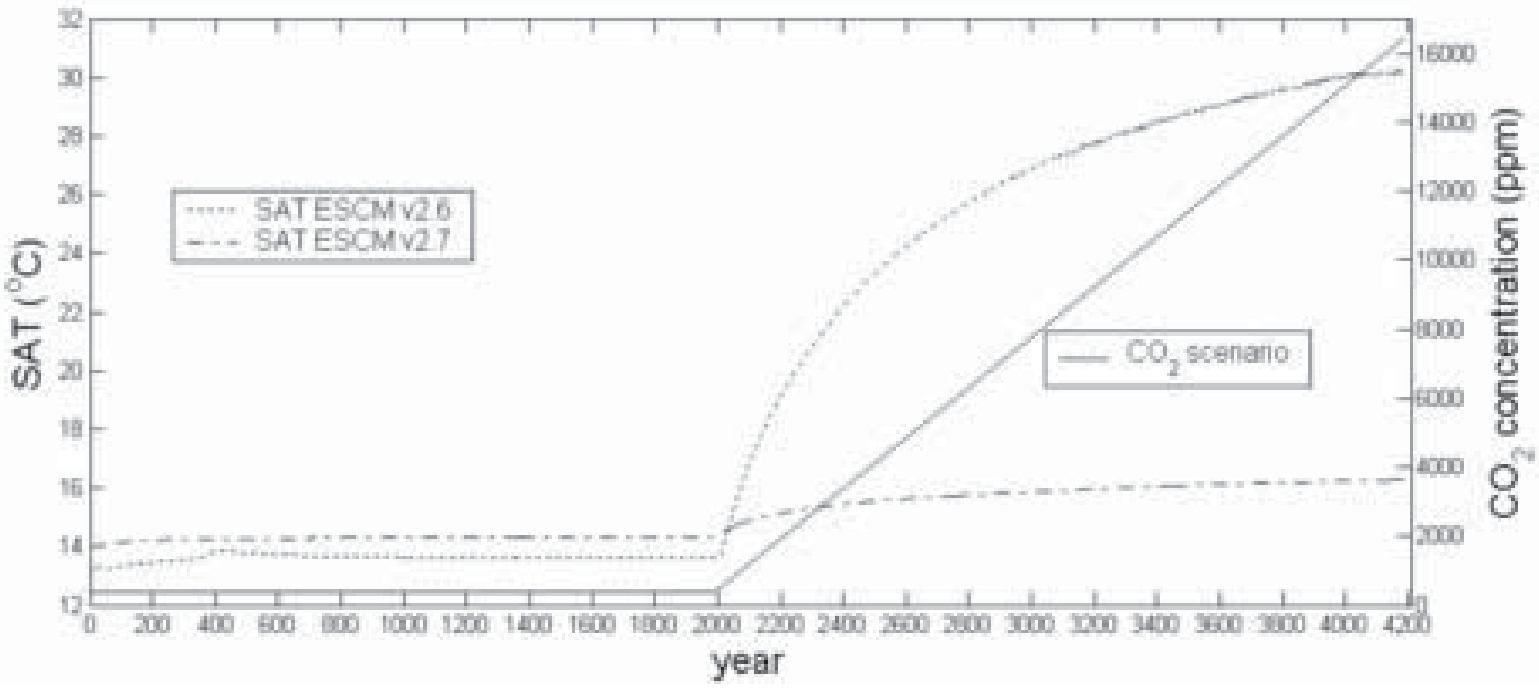




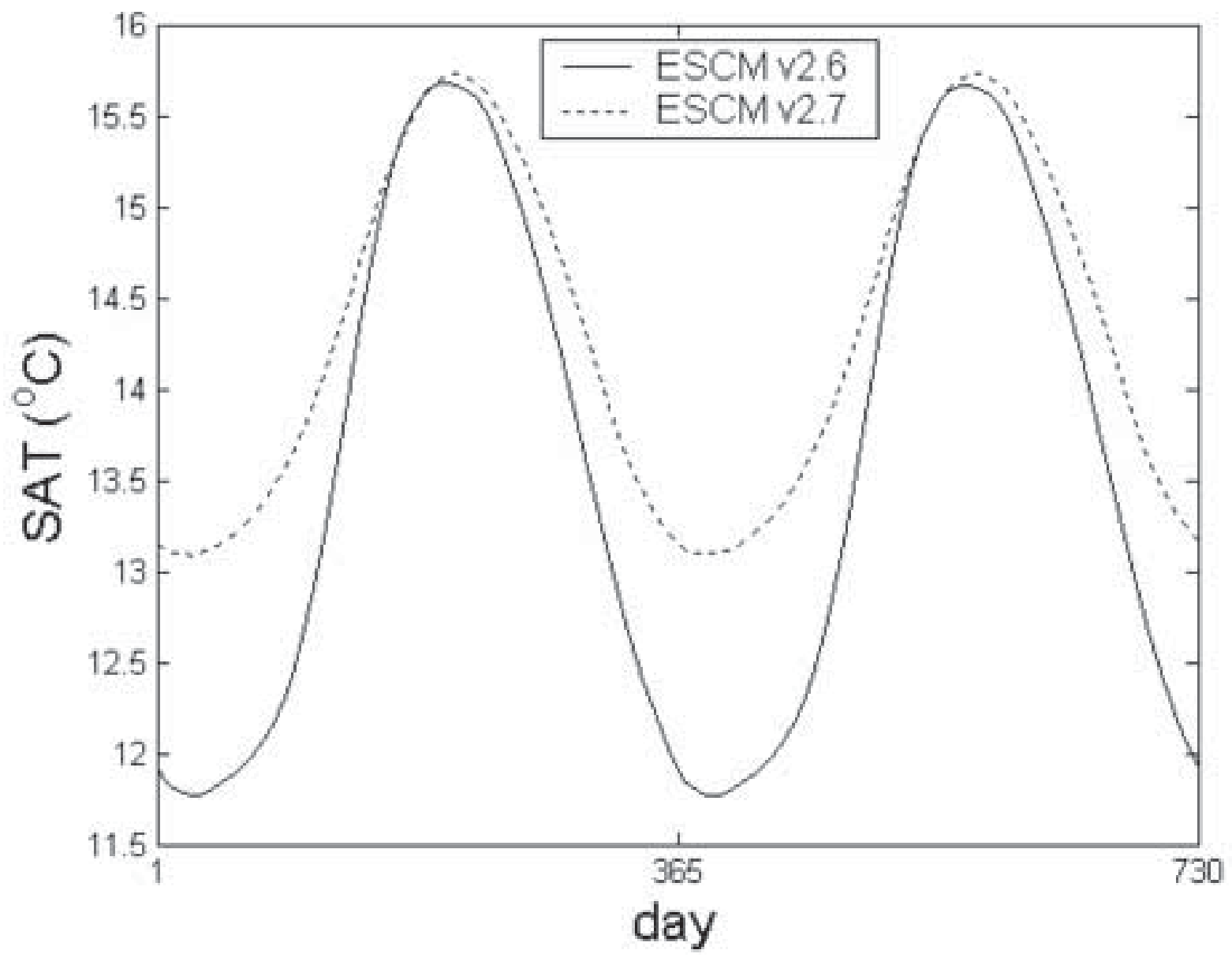


Figure(s) 2 top

Click here to download high resolution image

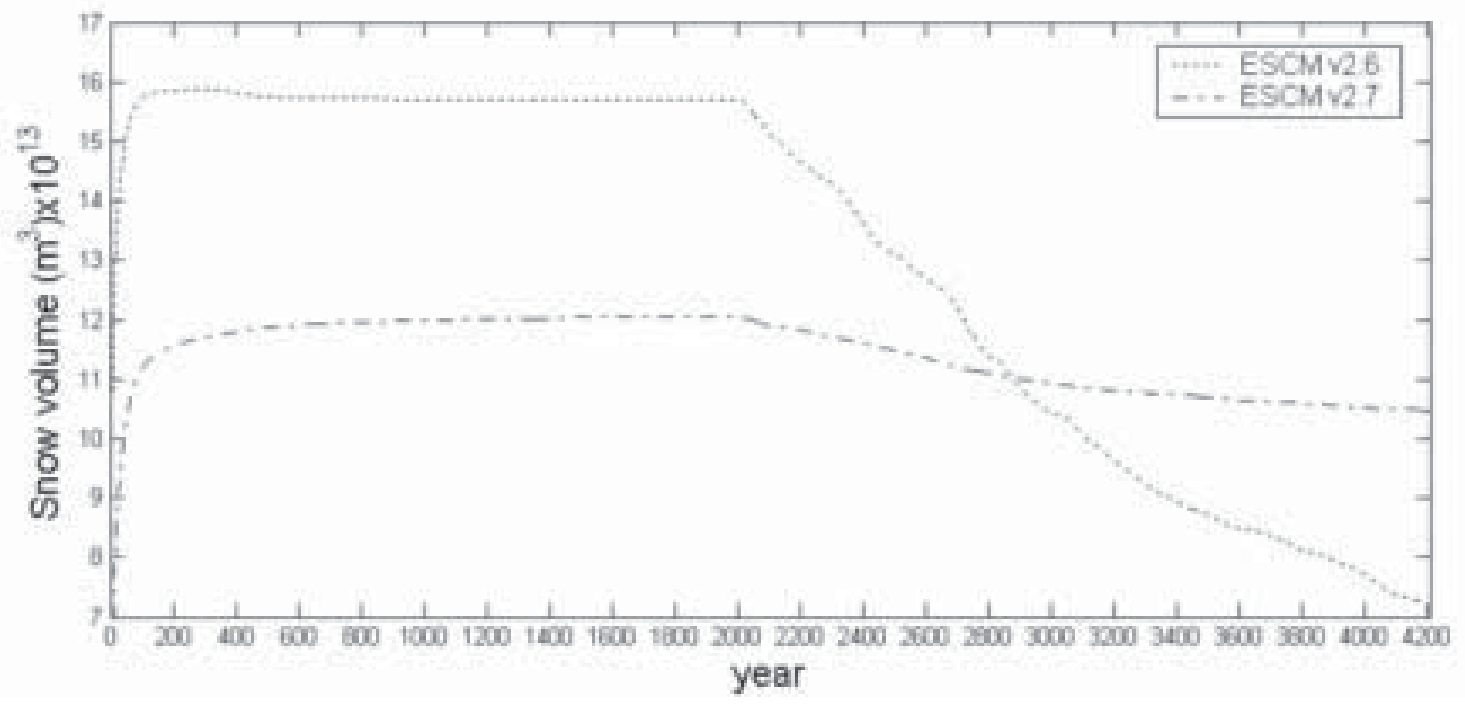




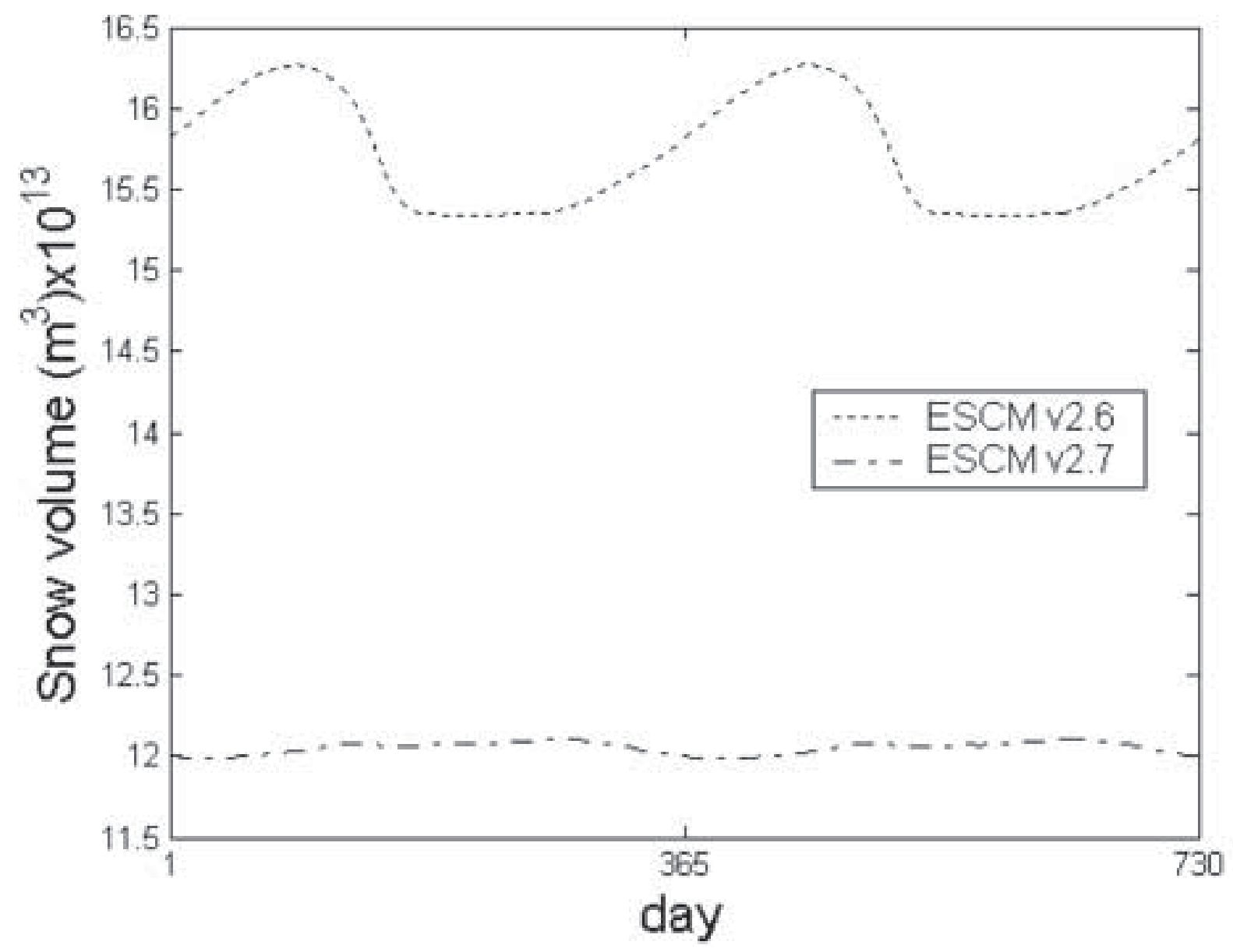


Figure(s) 3 top

Click here to download high resolution image

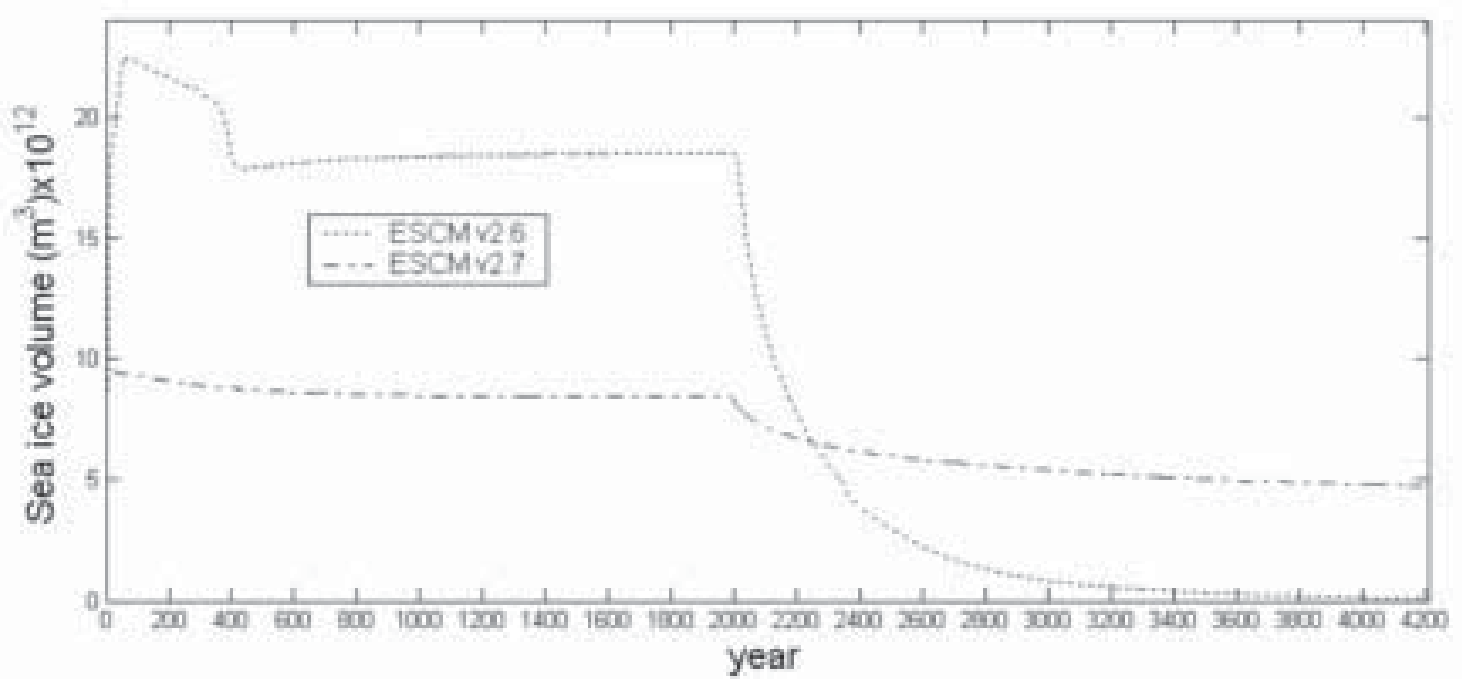




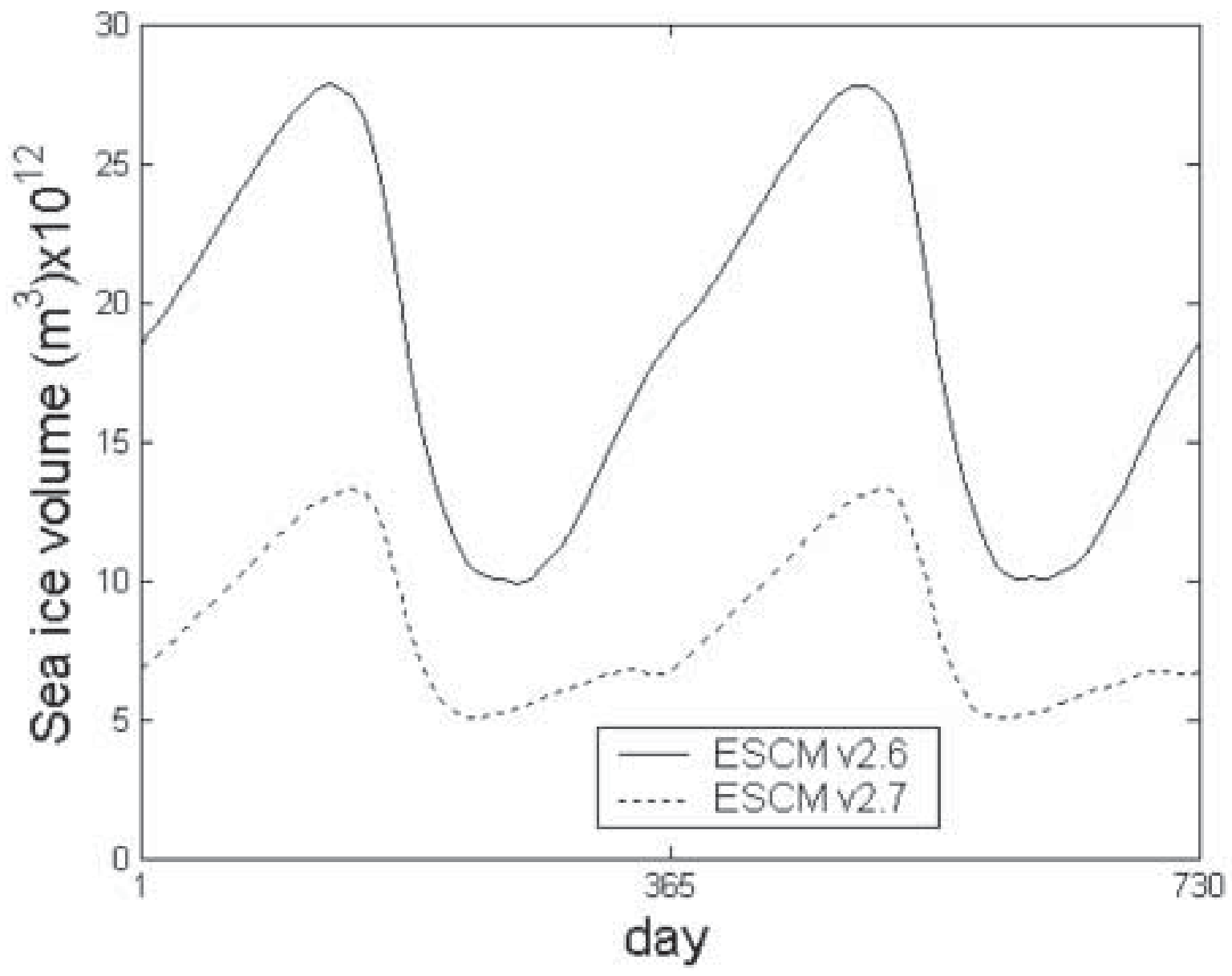


Figure(s) 4

Click here to download high resolution image

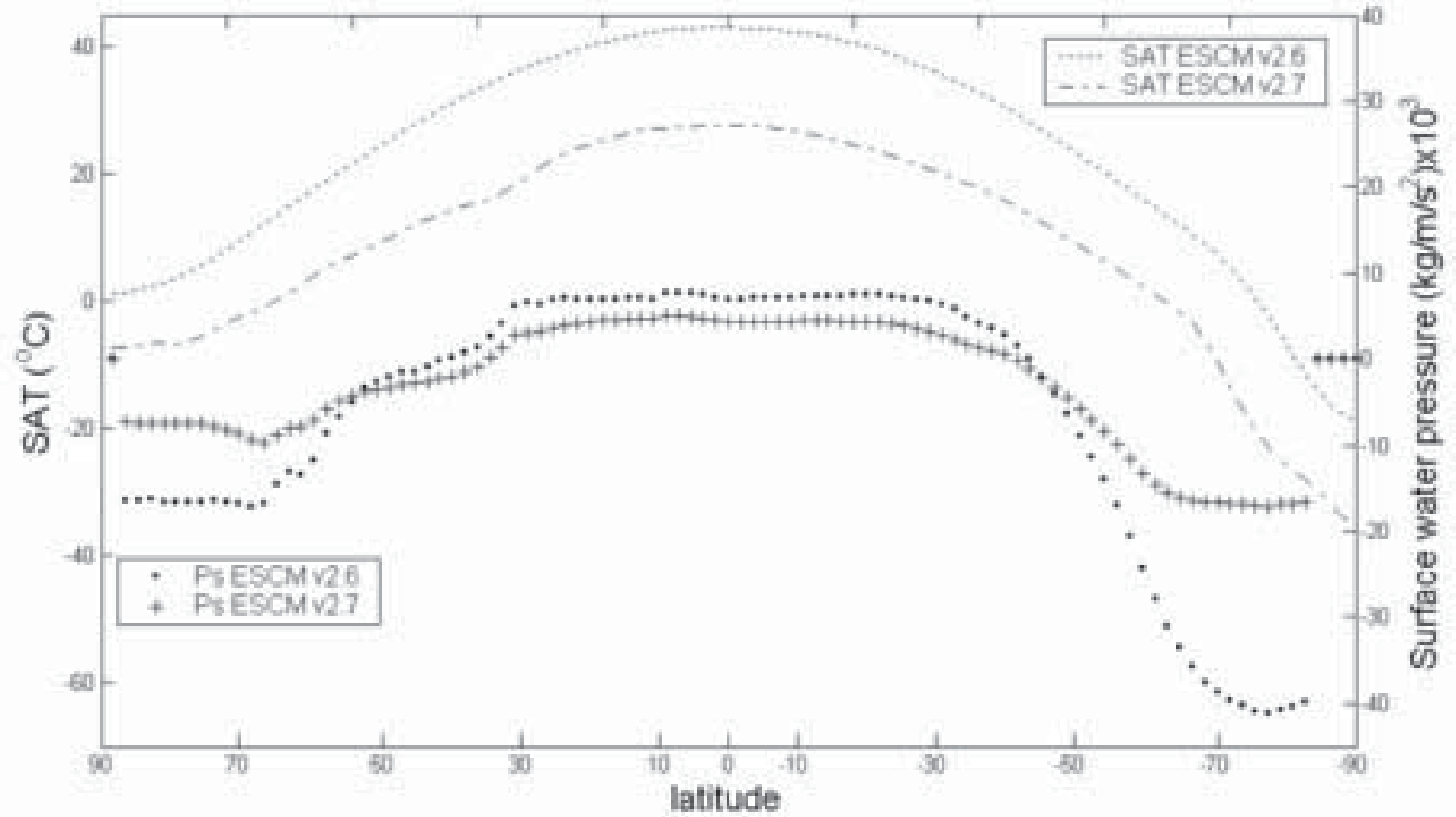


Figure(s) 5

Click here to download high resolution image

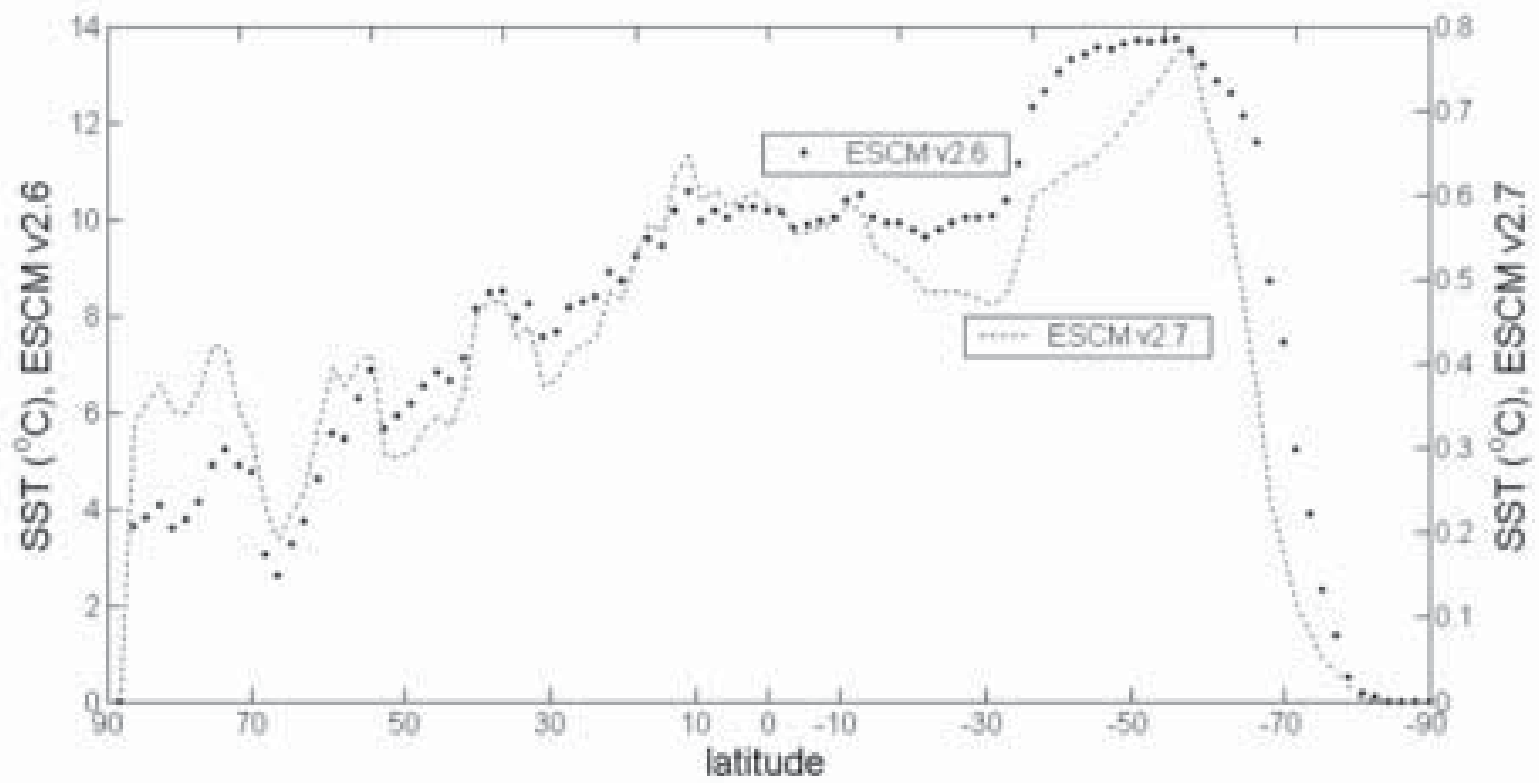


Click here to download high resolution image
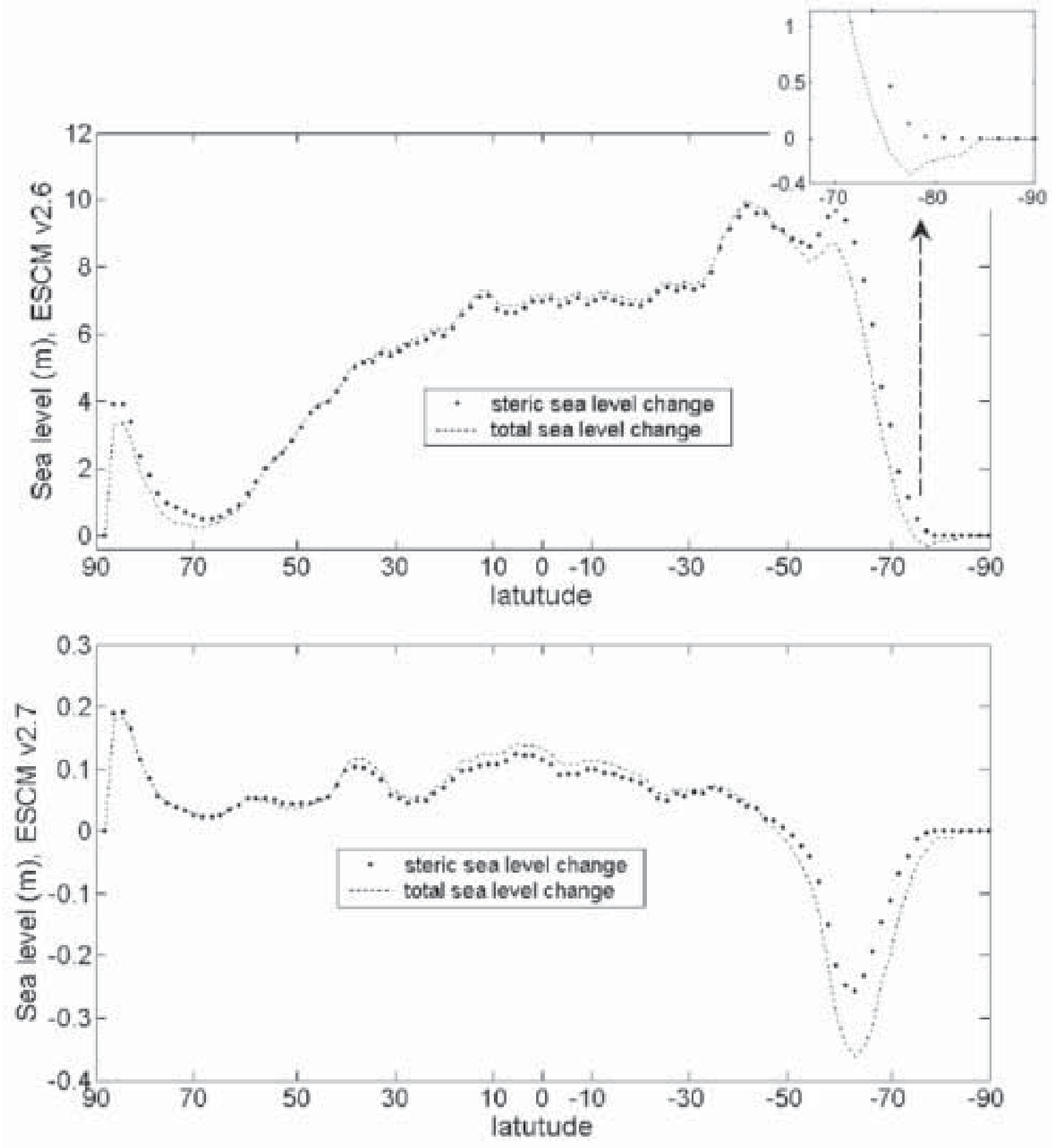


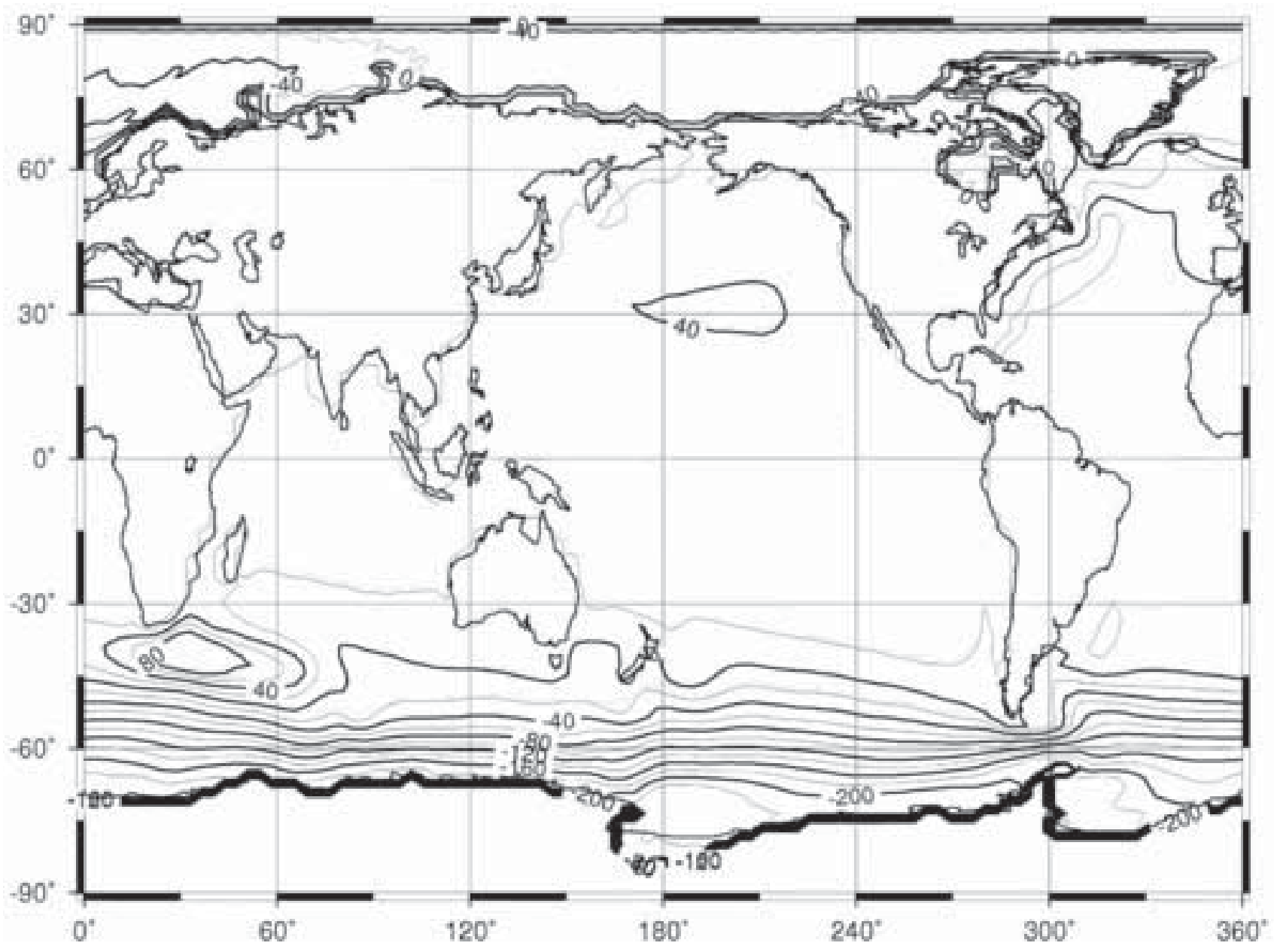




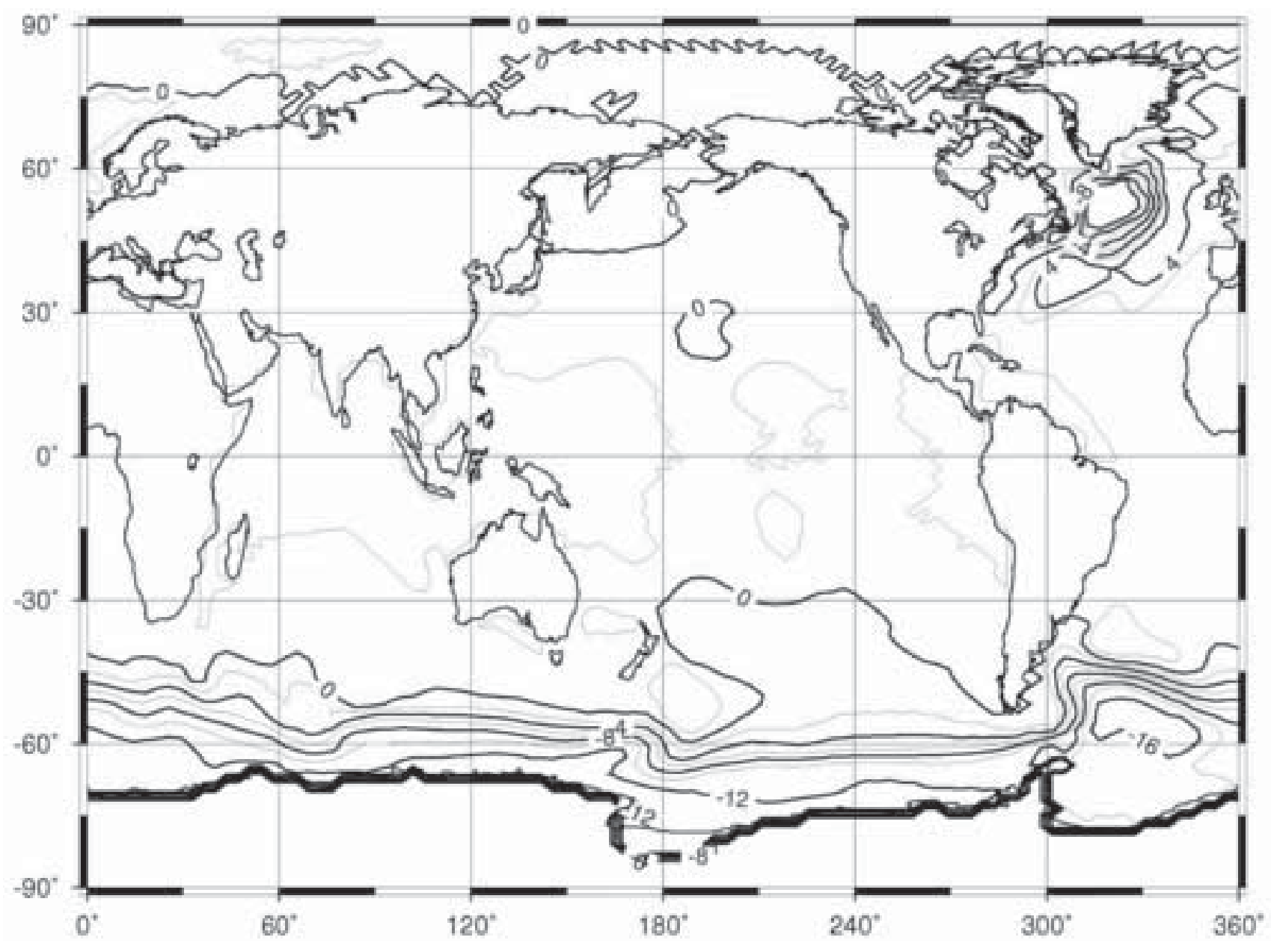




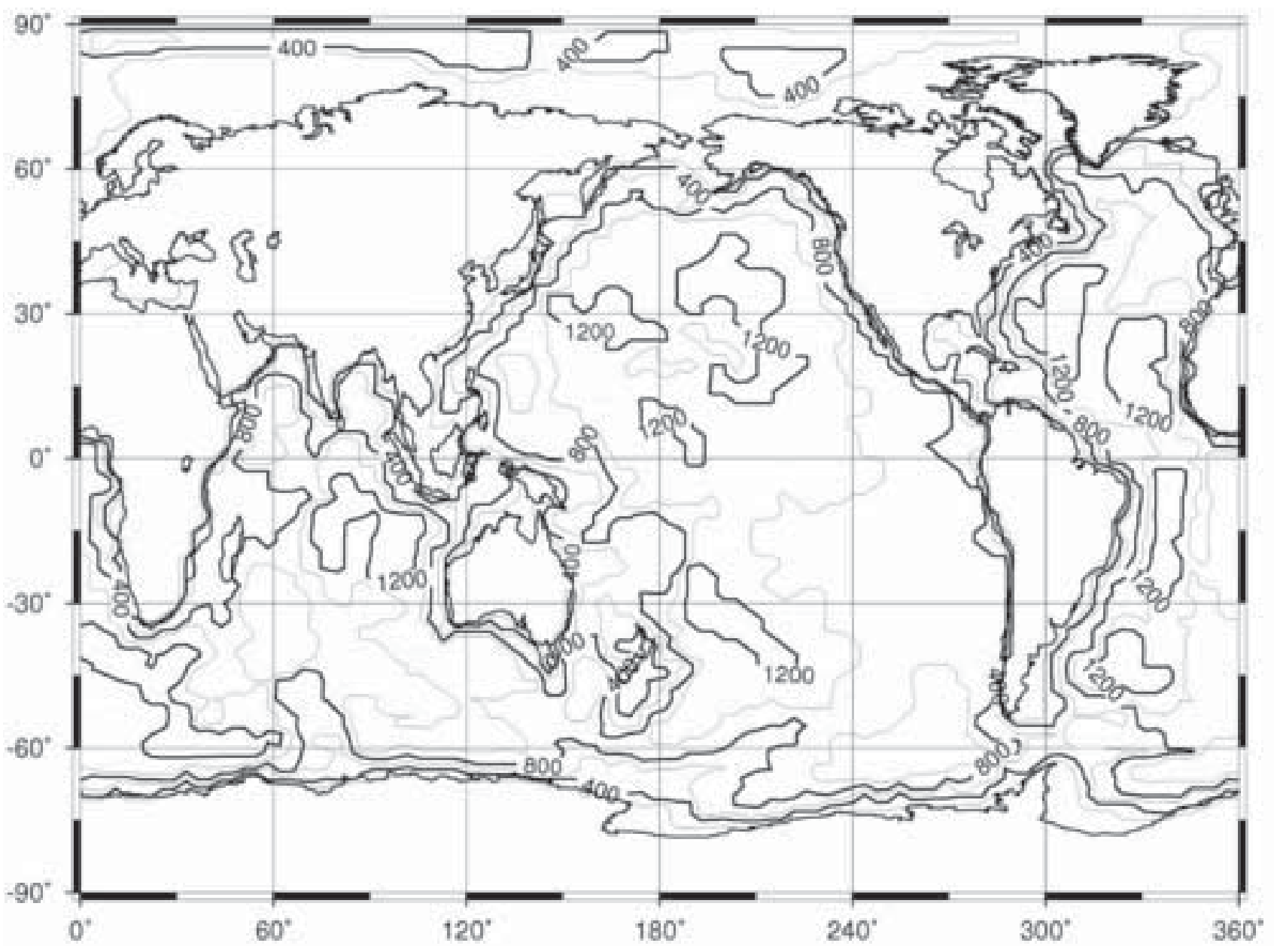




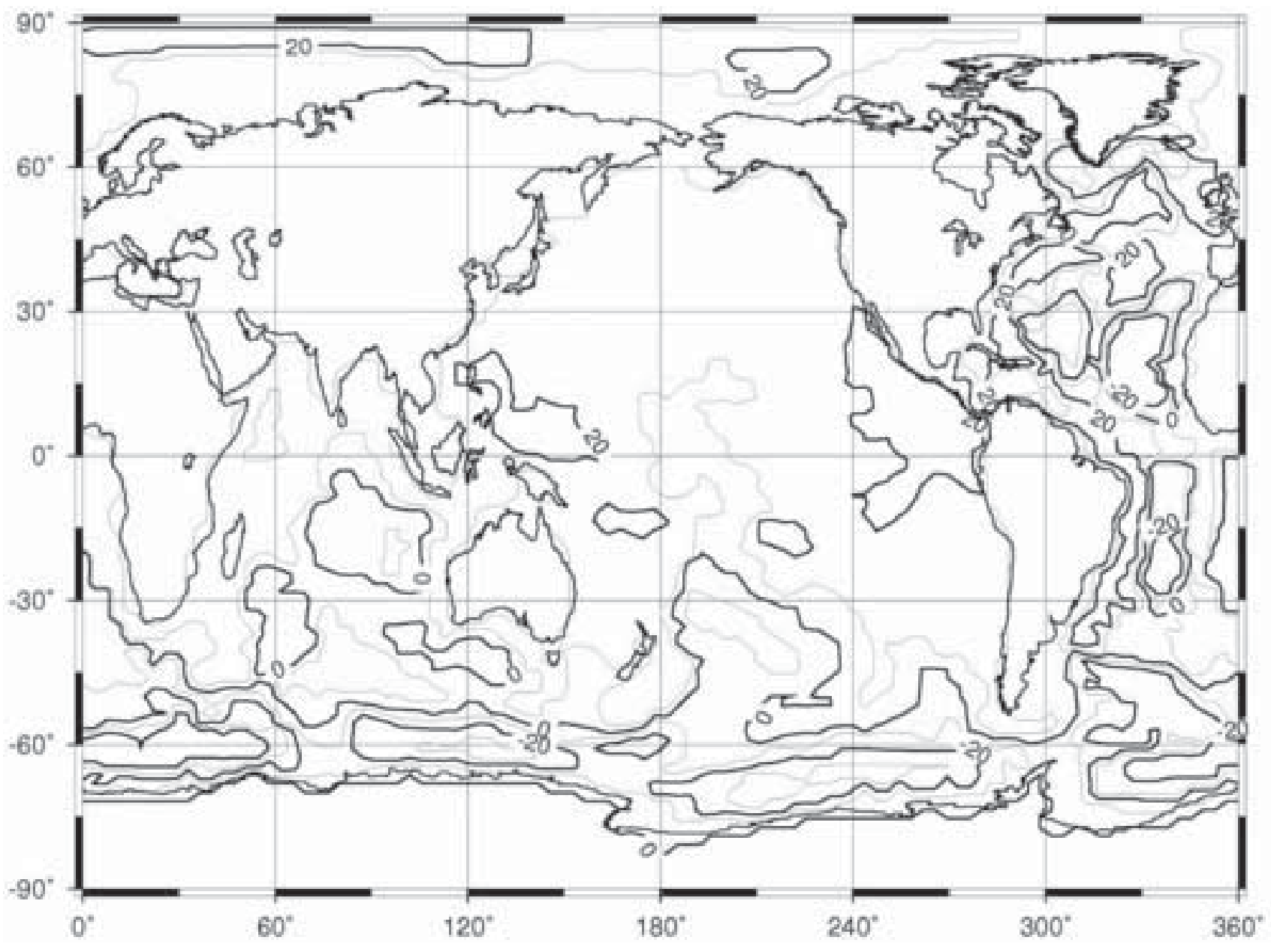




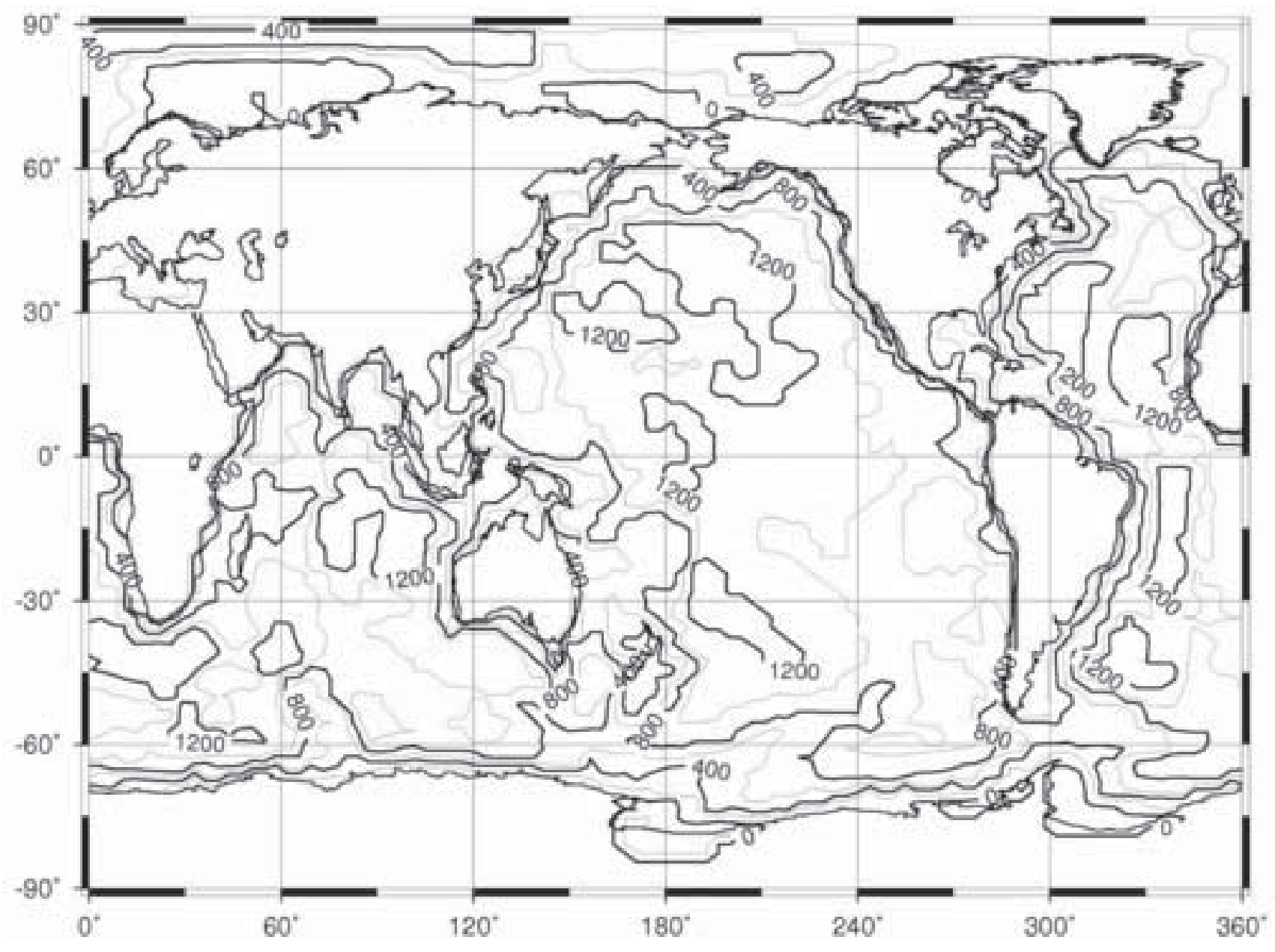




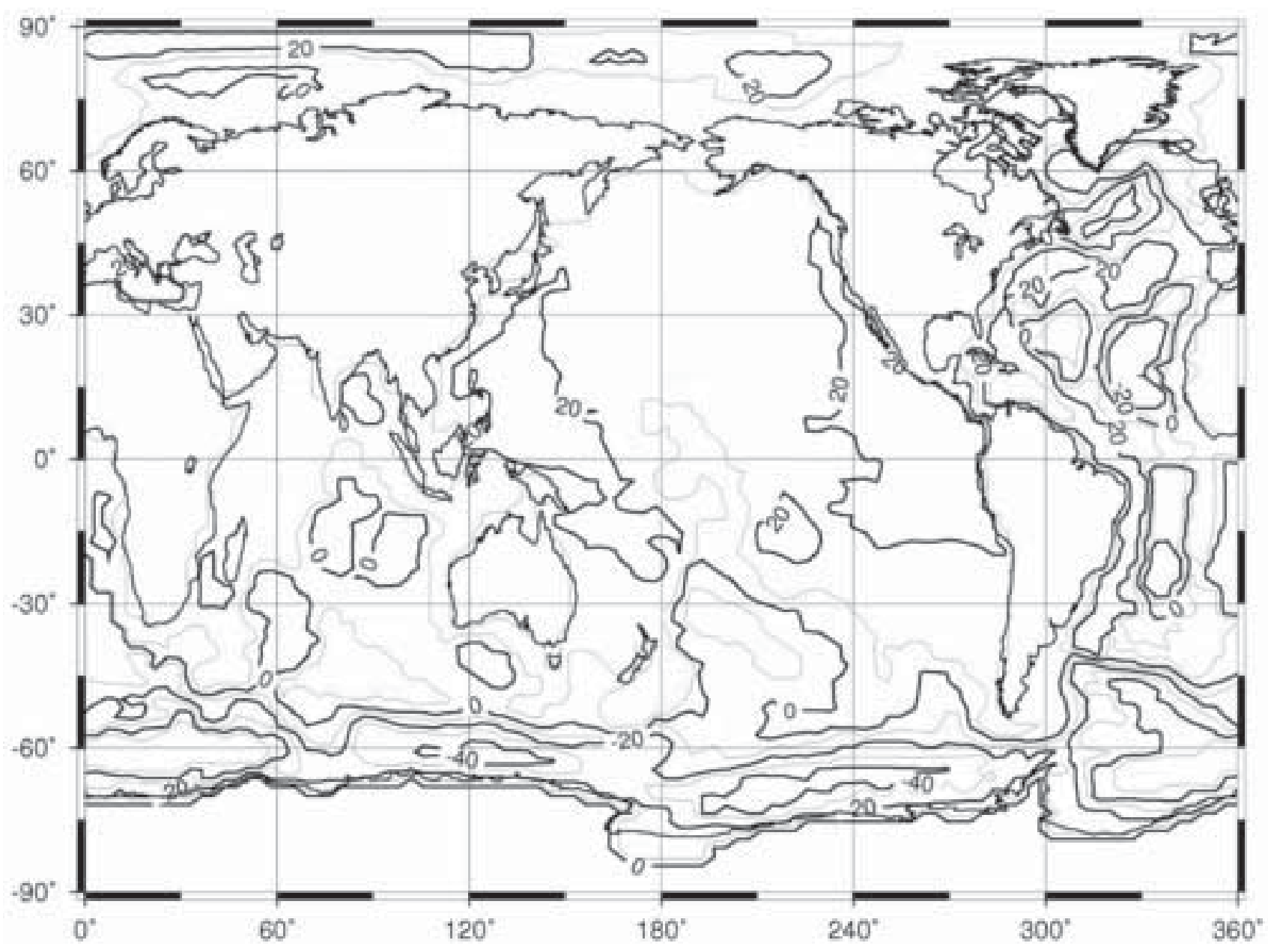


Figure(s) 10 top

Click here to download high resolution image

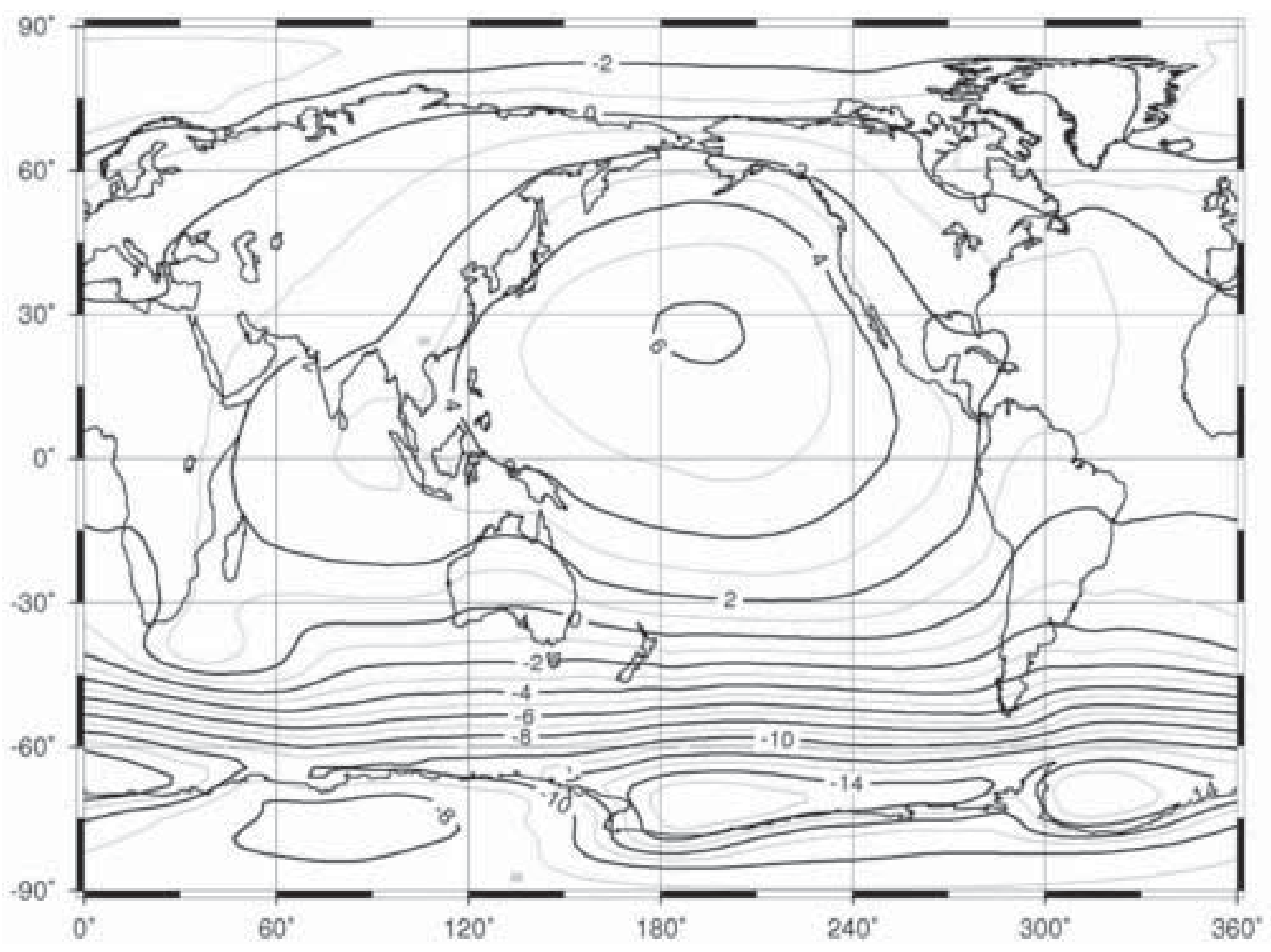




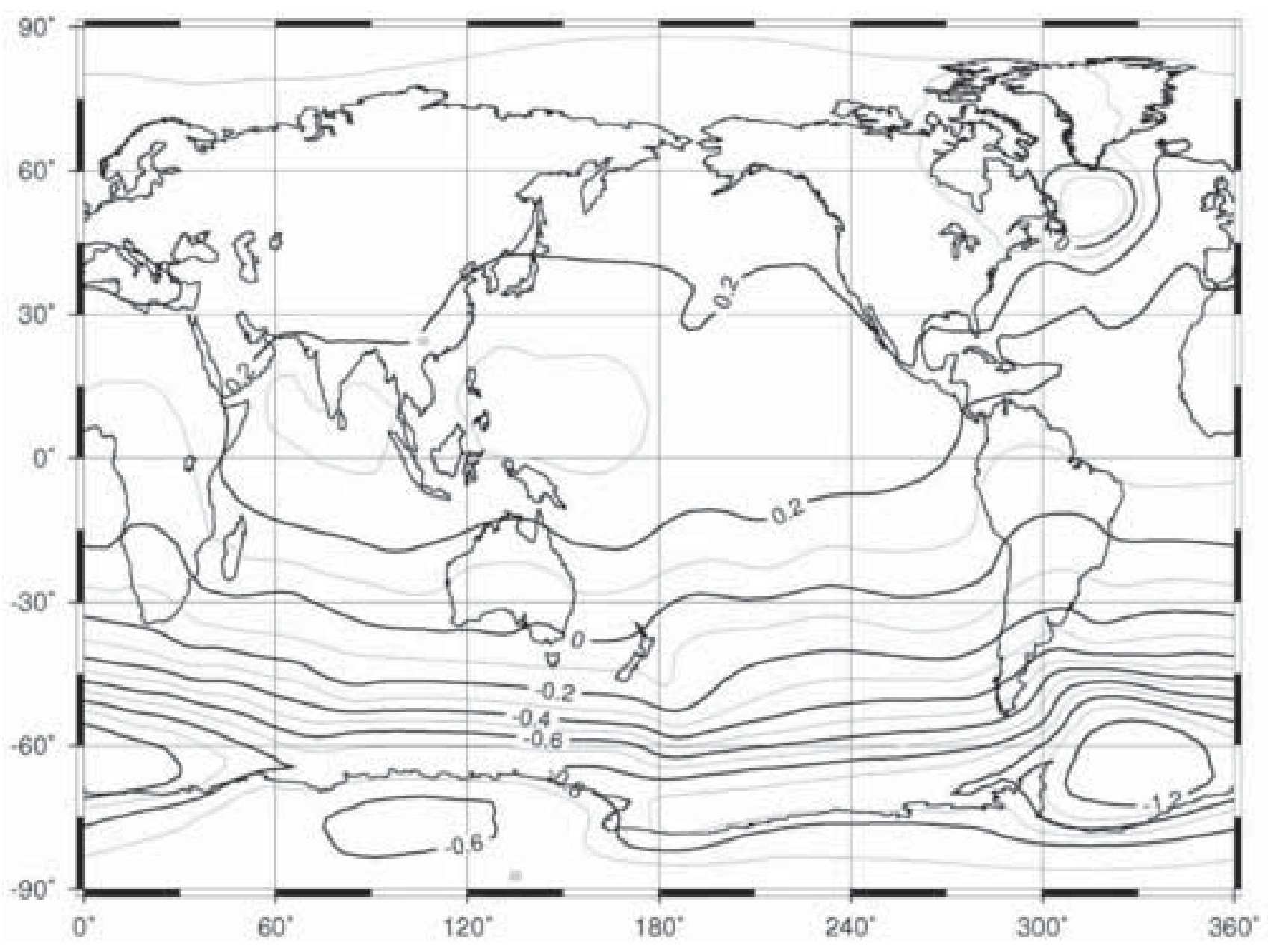

